\title{
PREDISPOSIÇÃO AO USO E ABUSO DE ÁLCOOL ENTRE ESTUDANTES DE GRADUAÇÃO EM ENFERMAGEM DA UFRN
}

\author{
Predisposition to the Use and Abuse of Alcohol \\ among Students of Graduation in Nursing of UFRN \\ La Predisposición al Uso y Abuso de Alcohol entre \\ Estudiantes de Graduación en Enfermería de la UFRN
}

Francisco Arnoldo Nunes de Miranda ${ }^{1}$

Isabelle Pinheiro de Macedo ${ }^{4}$

\author{
Dulcian Medeiros de Azevedo $^{2}$ \\ Tersila Gardênia Brito e Medeiros ${ }^{5}$
}

Raionara Cristina de Araújo Santos 3

\begin{abstract}
Resumo
Estudo de natureza exploratória descritiva com abordagem quantitativa, avaliou a predisposição para o uso e abuso do álcool na Graduação em Enfermagem/UFRN. A amostra foi composta por 42 alunos regularmente matriculados, sendo $76 \%$ do gênero feminino. Utilizou-se o questionário CAGE acrescido de itens sobre a síndrome da abstinência alcoólica. Metade (50\%) faz uso de álcool, com idade entre 21 e 22 anos (41\%). 0 maior consumo está no quinto período (38\%), seguido do terceiro (19\%). Dentre os pesquisados, $34 \%$ sentem-se fisicamente mal após beberem, $33 \%$ tropeçam, cambaleiam e trançam as pernas, e $33 \%$ sentem calor e suam. No que se refere aos sintomas mentais e emocionais, $50 \%$ referiram lentidão do raciocínio, 25\% sensações estranhas e assustadoras quando bebem, e 25\%, perda da memória. Conclui-se que há predisposição para o uso e abuso do álcool, e uma tendência ao alcoolismo feminino.
\end{abstract}

Palavras-chave: Alcoolismo. Transtornos Induzidos por Abuso de Álcool. Enfermagem. Estudantes de Enfermagem. Pesquisa em Avaliação de Enfermagem.

Abstract

Study of descriptive exploratory nature with quantitative approach, evaluated the predisposition for the use and abuse of the alcohol in the Graduation in Nursing/UFRN. The sample was composed by 42 students regularly enrolled, being $76 \%$ of the feminine gender. The CAGE questionnaire was used added of items on the syndrome of the alcoholic abstinence. Half $(50 \%)$ makes use of alcohol, with age among 21 to 22 years $(41 \%)$. The largest consumption is in the fifth period (38\%), following by the third period (19\%) among researched them, $34 \%$ felt bad physically after having drunk, $33 \%$ trip, sway and braid the legs, and $33 \%$ felt hot and sweat. In what refers to the mental and emotional symptoms, $50 \%$ referred slowness of the reasoning, $25 \%$ strange and frightening sensations when they drink, and $25 \%$ loss of the memory. It was ended that there is predisposition for the use and abuse of the alcohol and a tendency to the feminine alcoholism.

Keywords: Alcoholism. Alcohol-Induced Disorders. Nursing. Students of Nursing. Nursing Evaluation Research.

\section{Resumen}

El estudio de naturaleza exploratoria descriptiva con el acercamiento cuantitativo, evaluó la predisposición para el uso y abuso del alcoholen la Graduación en enfermería/UFRN. La muestra estaba regularmente compuesta por 42 estudiantes se enrollados, mientras siendo $76 \%$ del género femenino. La CAGE investigación se usó agregada de artículos enel síndrome de la abstinencia alcohólica. Medio (50\%) hace uso de alcohol, con la edad entre 21 a 22 años (41\%). El consumo más grande está en el quinto período (38\%), siguiendo por la tercera período (19\%) entre los investigó, 34\% se sentían males físicamente después de haber bebido, $33 \%$ viaje, oscilacióny trenza las piernas, y $33 \%$ se sentían calientes y sudor. En lo que se refiere a los síntomas mentales y emocionales, $50 \%$ se refirieron lentitud del razonamiento, 25\% sensaciones extrañas y aterradoras cuando ellos beben, y $25 \%$ pérdida de la memoria. Se acabó que hay predisposición para el uso y abuso del alcohol, y una tendencia al alcoholismo femenino.

Palabras clave: Alcoholismo. Trastornos Inducidos por Alcohol. Enfermería. Estudiantes de Enfermería. Investigación en Evaluación de Enfermería. 


\section{INTRODUÇÃO}

O uso abusivo do álcool e de outras drogas constitui, atualmente, um problema de Saúde Pública em função de sua complexidade e magnitude, visto que seus efeitos afetam, significativamente, a saúde e a qualidade de vida dos usuários e familiares.

0 uso abusivo de drogas é apresentado à população como vinculado às drogas lícitas - exatamente as mais consumidas - inteiramente livres para o consumo, o qual é alimentado por propagandas que as colocam como caminho do sucesso e sinônimo de alegria, beleza e juventude $e^{1: 601}$.

Particularmente, o álcool é, per si, uma droga referendada pela sociedade brasileira. 0 uso abusivo ou problemático do álcool é uma doença que causa morte ou limitações individuais e funcionais, neurológicas, gastrintestinais, cardiovasculares e psiquiátricas, e limitações coletivas, como 0 aumento nos índices do absenteísmo, da violência urbana, doméstica e intrafamiliar, e dos acidentes de trânsito, dentre outros impactos negativos ao convívio social, seja este pessoal ou profissional.

0 Brasil, através do Ministério da Saúde, adotou a política de atenção integral a usuários de álcool e outras drogas², regulamentou o atendimento aos dependentes nos Centros de Atenção Psicossocial (CAPS-ad), com a Portaria n 816/GM, e, por fim, estabeleceu o Sistema Nacional de Políticas Públicas sobre Drogas (SISNAD), através do Decreto n 5.912, de 27 de setembro de 2006.

0 Estado brasileiro e a sociedade pactuaram 0 compromisso e a responsabilidade no SISNAD, respeitando-se a diversidade e as especificidades populacionais existentes, tais como os fatores de proteção contra o uso indevido de drogas, preferencialmente, o álcool. Nesta perspectiva, recoloca o uso problemático do álcool na esfera da atenção primária como mecanismo estratégico para a redução do impacto negativo individual e social, além de promover uma melhoria no total de anos de vida ajustados por incapacitação (AVAl) perdidos em virtude do seu consumo.

O I Levantamento Nacional Domiciliar sobre o uso de drogas psicotrópicas, realizado em 2001, com participação de 107 cidades brasileiras de população superior a 200.000 habitantes, revelou que o consumo de álcool na população total era de $68,7 \%$. Dos entrevistados com idade entre $12 \mathrm{e}$ 17 anos, 48,3\% relataram uso de bebidas alcoólicas, e 0 percentual foi de $73,2 \%$ nos de faixa etária entre 18 e 24 anos. A maior ocorrência (acima dos 16\%) de dependência do álcool foi encontrada nas regiões Norte e Nordeste. Fato mais preocupante foi a informação de que $5,2 \%$ dos adolescentes (12 a 17 anos) eram dependentes do álcool. No Norte e Nordeste, essa porcentagem ficou próxima dos $9 \% 3$.

Noutro estudo, o uso do álcool nas 107 maiores cidades brasileiras foi de $68,7 \%$, porcentagem próxima aos $71,0 \%$ no Chile e aos 81,0\% nos EUA, com proporções mais ou menos estáveis para as diferentes faixas etárias ${ }^{4}$.

No Brasil, o uso do álcool foi maior para o sexo masculino $(77,3 \%)$ quando comparado ao feminino $(60,6 \%)$, aproximando-se ao observado na Colômbia, com $48,1 \%$ para homens e 23,6\% para mulheres, distante dos percentuais do Chile e dos EUA. No Chile e nos EUA, o uso do álcool foi de
$87,3 \%$ e $86,6 \%$ entre os homens, $80,5 \%$ e $78,5 \%$ entre as mulheres, respectivamente ${ }^{4}$.

0 álcool é uma droga que produz no ser humano uma ação euforizante, ao lado de seu efeito depressor, que pode ser traduzido pela desinibição comportamental, hilaridade, expressões afetivas aumentadas e diminuição da autocrítica. Em complemento, o segmento populacional jovem é o mais vulnerável ao uso e abuso do álcool e outras drogas 5 . Os jovens encontram-se em uma fase da vida em que a busca pelo novo se dá de forma constante e explosiva, iniciando o uso do álcool na adolescência em $20 \%$ dos homens e em $8 \%$ das mulheres ${ }^{5}$.

As limitações físicas ou crônicas, a baixa auto-estima, os temores e as dificuldades para estabelecer relações interpessoais, a falta de habilidade para resolver problemas, a baixa tolerância à frustração, ao fracasso e à dor, a insegurança, a timidez e a instabilidade emocional são fatores que induzem 0 jovem ao consumo do álcool. Em adição, também existe a busca por sensações novas, desejo de independência, crise do desenvolvimento e crescimento, imitação de pessoas famosas, pressão do grupo de amigos, confusão de valores, carência de alternativas de lazer ${ }^{6-7}$.

0 ambiente familiar, contraditoriamente, por ser a base para uma adequada saúde física e emocional, além de transmitir valores essenciais ao desenvolvimento do jovem, é tido como um espaço de convivência da prática de consumo do álcool ${ }^{7}$. Problemas como ausência de diálogo, conflitos intergeracionais, violência intrafamiliar, falta de confiança, dificuldade para aceitar o comportamento dos filhos, entre outros, correspondem a fatores de risco para o uso e abuso do álcool e outras substâncias psicoativas ${ }^{7}$.

0 controle do uso do álcool na sociedade brasileira ocorre de forma inadequada, quer pelo baixo custo da aguardente (menos de meio dólar), quer pela venda indiscriminada de bebidas alcoólicas ${ }^{8}$. 0 álcool não é, e está longe de ser considerado um produto qualquer, causando diversos danos através de três mecanismos: toxicidade sobre vários órgãos e sistemas corporais; intoxicação aguda; e dependência. 0 padrão de consumo caracteriza-se não somente pela freqüência e pela quantidade, mas também pelo tempo entre um episódio e outro ${ }^{8}$.

0 uso e abuso do álcool, também entendido como uso problemático do álcool, pode acarretar no indivíduo sintomas da síndrome da abstinência do álcool (SAA), marcada pelo quadro de desconfor to físico, com tremores, náuseas, vômitos, sudorese, desconfor to afetivo, irritabilidade, ansiedade, inquietação e alterações psíquicas (alucinações, ilusões, pesadelos) $)^{9}$. Esta terminologia não se aplica somente ao dependente ou ao usuário que chega ao serviço de saúde com halitose alcoólica, intoxicado ou com SAA, mas a um padrão que pode ser o de beber excessiva e diariamente, ou em repetidos episódios de intoxicação alcoólica ${ }^{10}$.

Para cuidar desses usuários nos serviços, e por recomendações da Organização Mundial de Saúde (OMS), foram criadas as Estratégias de Diagnóstico e Intervenções Breves (EDIBs) em atenção primária a serem inseridas na Estratégia Saúde da Família (ESF), como forma de prevenir os danos causados à saúde pelo uso do álcool e por ser um dos dez problemas prioritários em Saúde Pública no país ${ }^{10-11}$. As EDIBs têm como objetivos reconhecer e assistir os pacientes 
no processo de tomada de decisão, e em esforços para redução ou interrupção da ingesta alcoólica antes do desenvolvimento de sérios problemas físicos, psicológicos ou sociais ${ }^{11}$.

Estudo bibliográfico sobre o manejo da enfermagem em relação ao uso do álcool e drogas, e sua complexidade, identificou e comparou os modelos explicativos usados, como: o ético-legal, o moral, o médico ou da doença, o psicológico ou psicossocial e o sociológico ou sócio-cultural, concluindo que há uma produção significativa de experiências com a prática da enfermagem na assistência, pesquisa e ensino relacionada ao alcoolismo ${ }^{7}$.

Como tentativas teóricas, sugere que o conhecimento dos modelos explicativos faculta ao enfermeiro meios para facilitar sua prática de acordo com as necessidades da demanda de saúde, além da garantia de um ambiente acolhedor, empático, motivacional, conduzindo ao relacionamento interpessoal ${ }^{7}$.

Outro estudo bibliográfico sobre o uso abusivo de drogas entre os profissionais de saúde apontou a susceptibilidade para a automedicação pelo livre acesso dos mesmos em seu trabalho.

[...] como uma maneira de minimizar a síndrome do desgaste profissional com desenvolvimento de outros desequilibrios, além de infringir os preceitos éticos e estéticos da profissão, pois o efeito da droga altera o comportamento, o raciocínio lógico, a tomada de decisões e a execução de procedimentos especializados, colocando em risco a vida das pessoas sob seus cuidados e comprometendo a sua própria saúde ${ }^{1: 599}$.

Entretanto, no campo da Enfermagem, entende-se que o estudo deve se basear no contexto dos sujeitos envolvidos, em suas fragilidades e motivações (indivíduo e seus familiares). Isto porque a prática da enfermagem exige do profissional um senso investigativo das informações verbais ou contextuais, além das formas de silêncio ou ocultamento de certas problemáticas geradoras de saberes e práticas mais adaptadas e mais humanizadas no atendimento ao alcoolista e sua família' ${ }^{12}$.

Estudos evidenciam a vulnerabilidade à dependência de médicos e enfermeiros por certas drogas, pois lidam com elas em seu processo de trabalho, devido à maior possibilidade de auto-administração, pelo livre acesso, dada a responsabilidade do armazenamento e controle ${ }^{13}$.

0 alcoolismo, ou a dependência ao álcool, possui um forte estigma social, assim como a maioria dos diagnósticos de transtornos mentais. E os usuários, como mecanismo de fuga desse estigma, geralmente não assumem sua condição de alcoolistas, negando o transtorno apresentado, o que dificulta a recuperação. Exigir que a pessoa reconheça seu quadro patológico implica um enfraquecimento da auto-estima e, conseqüentemente, uma condição insatisfatória para o êxito da terapêutica, sendo necessário contemplar a singularidade de cada indivíduo e suas implicações sociais por meio de estratégias que visem garantir a segurança dos envolvidos ${ }^{14}$.

As situações de entrada na universidade, afastamento da família, novos vínculos de amizade, participação em festas com uso de bebidas alcoólicas, entre outros, fazem parte de uma fase de mudança que pode provocar maior risco para o uso de substâncias, seja pela pressão dos amigos ou pelo sentimento de independência. Além disso, gera-se um ambiente favorável à ocorrência de comportamentos inesperados, como dirigir embriagado, fazer sexo sem proteção ${ }^{14}$.

De uma maneira geral e peculiar, algumas características são observáveis cotidianamente no favorecimento do consumo de álcool, quer ocasional, quer problemático ou abusivo, especialmente se considerarmos a cultura local e regional nordestina, com grandes festejos populares (juninos, religiosos), o carnaval fora de época, a cultura do forró eletrônico.

No âmbito da academia, os jovens universitários possuem um modo comum de diversão quase sempre acompanhado pelo consumo de bebidas alcoólicas, seja nas calouradas, feijoadas, churrascos, cantinhos universitários, "baladas". Nesse sentido, investigar a predisposição de universitários ao uso e abuso de álcool pareceu aos autores uma preocupação premente, pois, per si, representa uma atividade de promoção à saúde mental e física dos estudantes.

Diante do exposto, objetivou-se analisar a predisposição ao uso e abuso de álcool entre os estudantes do Curso de Graduação em Enfermagem da Universidade Federal do Rio Grande do Norte (UFRN).

\section{METODOLOGIA}

Estudo exploratório e descritivo, com abordagem quantitativa. Cabe ao pesquisador no estudo descritivo observar, descrever e documentar os aspectos de determinada situação ou fenômeno, sem se preocupar em estabelecer relações de causa e efeito ${ }^{15}$. 0 estudo exploratório e descritivo tem o objetivo de proporcionar uma visão geral de tipo aproximativo, sobre determinado fato, consistindo na análise e descrição de características ${ }^{16}$.

Os dados foram coletados em junho de 2006 no Departamento de Enfermagem da UFRN, tendo como sujeitos de pesquisa os alunos do Curso de Graduação em Enfermagem, regularmente matriculados nos nove períodos letivos, totalizando uma população de aproximadamente 420 acadêmicos.

Os critérios de inclusão foram: estar regularmente matriculado no semestre letivo correspondente ao período de coleta dos dados; responder às perguntas de corte antes da aplicação do instrumento de pesquisa.

Definiu-se a priori uma amostra correspondente a $20 \%$ da população, ou seja, 84 alunos. Todavia, a pergunta de corte, "0 Sr(a) bebe?", determinou, coincidentemente e eqüitativamente, a recusa e a participação da amostra no estudo, não sendo objeto de discussão a recusa dos alunos abordados. Desse artefato, a amostra foi do tipo não-probabilística, composta por 42 acadêmicos, totalizando $10 \%$ da população.

Utilizou-se como marco divisório o transcurso do processo ensino-aprendizagem facultado pela disciplina Clínica Ampliada no Contexto da Saúde Mental, ofertada no quinto período do curso, por ser a única que aborda o assunto do uso e abuso de substâncias psicoativas em seu conteúdo programático, embora coexista a preocupação noutras disciplinas como temas transversais. Por exemplo, na saúde do trabalhador, além da 
matriz curricular do novo Projeto Político Pedagógico do Curso a ser implantado após os trâmites institucionais que priorizam a temática na atenção básica, clínica ampliada e avançada.

Concorda-se que na escolha por uma determinada escala de avaliação, devem-se levar em consideração as características, as variações dos instrumentos e a validação da mesma no país. As escalas apresentam diferentes finalidades, as quais dizem respeito ao objetivo e à utilidade clínica, ao período de tempo em que se pretende avaliar, à populaçãoalvo, à existência de normas, ao tipo de administração, ao nível de treinamento necessário e ao custo ${ }^{17}$.

Optou-se pela Escala de CAGE $^{18}$, classificada como um instrumento, que avalia os objetivos do uso e abuso do álcool, para triagem de indivíduos que, provavelmente, apresentam problemas relacionados ao uso/abuso de álcool ou outras drogas, e não apenas para os casos diagnósticos da síndrome de dependência do álcool (SDA) ${ }^{18-19}$.

0 Questionário CAGE $^{18}$ traduzido e validado para 0 português tem por finalidade detectar problemas relacionados ao consumo de bebidas alcoólicas, com resultado de $88 \%$ para a sensibilidade (porcentagem de alcoolistas corretamente identificados) e de $83 \%$ para a especificidade (porcentagem de não-alcoolistas corretamente identificados) ${ }^{19}$.

É composto por quatro questões (cut down = diminuir; annoyed = aborrecer; guilt = culpa; eye opening = ao despertar $)^{18}$, constituindo-se num método de rápida e fácil aplicação, não requerendo muito treinamento dos aplicadores, ao mesmo tempo em que é de baixo custo, pouco intimidativo, com sensibilidade e especificidade comprovadas. Adotou-se o ponto de corte de acordo com os critérios de sensibilidade e especificidade, em duas respostas positivas ${ }^{18-19}$. Acrescentaram-se dados sócioculturais ao questionário e perguntas fechadas sobre as principais manifestações físicas e mentais, como provável indicativo da síndrome da dependência alcoólica.

Quando abordados, os sujeitos de pesquisa foram esclarecidos sobre o objetivo do estudo, com destaque para o sigilo e a confidencialidade das respostas direcionadas ao instrumento. Após aceite, procedeu-se à assinatura do Termo de Consentimento Livre e Esclarecido (TCLE) em respeito aos preceitos éticos da Resolução 196/96 do Conselho Nacional de Saúde.

Os dados foram codificados com as letras maiúsculas EE (Estudante de Enfermagem), seguidas dos numerais arábicos 1 a 9, compreendendo os períodos letivos definidos pelo Projeto Político Pedagógico do Curso, e por outro numeral, seqüencialmente, na medida em que respondiam ao questionário (Exemplo: $E_{1} 1$ ). Posteriormente, foram submetidos ao recurso informacional do processador Microsoft Excel e apresentados em tabelas.

\section{RESULTADOS E DISCUSSÃO}

Em relação ao período curricular do curso à época da entrevista, a amostra se apresentou da seguinte maneira: $26 \%$ dos alunos estavam no $5^{\circ}$ período; $19 \%$, no $4^{\circ}$ período; $17 \%$, no $3^{\circ}$ período; $12 \%$, no $1^{\circ}$ período; $10 \%$, no $6^{\circ}$ período; $7 \%$, no $2^{\circ}$ período; $5 \%$, no $7^{\circ}$ período; e, igualmente, $2 \%$ no $8^{\circ}$ e $9^{\circ}$ períodos.
Optou-se por apresentar os resultados em dois momentos distintos, didaticamente intencionais, como forma de facilitar a clareza das idéias e a discussão dos resultados. Dessa forma, primeiro arrolou-se a caracterização dos sujeitos da pesquisa, seguida da predisposição dos acadêmicos ao uso e abuso de bebidas alcoólicas.

\section{Caracterização dos Sujeitos: dados de identificação e sócio-demográficos}

A distribuição dos estudantes de Enfermagem por faixa etária compreendeu $29 \%$ com menos de 20 anos, $61 \%$ de 21 25 anos, e $10 \%$ de $26-30$ anos, sendo $98 \%$ solteiros. Foi perguntado também com quem residiam ou se exerciam alguma profissão/ocupação. A maioria (76\%) disse morar com os pais ou outros familiares, $5 \%$ sozinhos, $7 \%$ com amigos e $12 \%$ não responderam. Em relação ao vínculo profissional e/ou ocupacional, 83\% afirmaram não exercer atividade profissional, dedicando-se exclusivamente à formação profissional.

A Tabela 1 diz respeito à distribuição dos estudantes por período letivo, gênero e consumo de bebida alcoólica. Dos entrevistados, $76 \%$ são do gênero feminino, e metade da amostra (50\%) confirmou o uso do álcool. Destes, $54 \%$ pertencem ao $5^{\circ}$ período, $19 \%$ ao $3^{\circ}$ e $14 \%$ ao $1^{\circ}$, perfazendo $87 \%$ dos que afirmar o uso. $05^{\circ}$ período, com maior positividade e tendência para o uso e abuso do álcool, concentra a maior participação do gênero masculino, com $26 \%$.

\section{Tabela 1 :}

Distribuição percentual e absoluta por períodos, consumo e gênero dos estudantes de Enfermagem da UFRN. Natal/RN Junho/2006.

\begin{tabular}{lcccccccccccc}
\hline \multicolumn{3}{c}{ Consumo } & \multicolumn{1}{c}{ Gêneros } \\
\multicolumn{4}{c}{ Sim } & \multicolumn{1}{c}{ Não } & Períodos & Fem. & \multicolumn{1}{c}{ Masc. } & Períodos \\
& Freq & $\%$ & Freq & $\%$ & Freq & $\%$ & Freq & $\%$ & Freq & $\%$ & Freq & $\%$ \\
\hline $\mathrm{EE}_{1}$ & 3 & 14 & 2 & 10 & 5 & 12 & 5 & 16 & - & - & 5 & 12 \\
$\mathrm{EE}_{2}$ & 2 & 10 & 1 & 5 & 3 & 7 & 2 & 6 & 1 & 10 & 3 & 7 \\
$\mathrm{EE}_{3}$ & 4 & 19 & 3 & 14 & 7 & 17 & 6 & 19 & 1 & 10 & 7 & 17 \\
$\mathrm{EE}_{4}$ & 3 & 14 & 5 & 23 & 8 & 19 & 5 & 16 & 3 & 30 & 8 & 19 \\
$\mathrm{EE}_{5}$ & 8 & 38 & 3 & 14 & 11 & 26 & 7 & 22 & 4 & 40 & 11 & 26 \\
$\mathrm{EE}_{6}$ & 1 & 5 & 3 & 14 & 4 & 10 & 3 & 9 & 1 & 10 & 4 & 10 \\
$\mathrm{EE}_{7}$ & - & - & 2 & 10 & 2 & 5 & 2 & 6 & - & - & 2 & 5 \\
$\mathrm{EE}_{8}$ & - & - & 1 & 5 & 1 & 2 & 1 & 3 & - & - & 1 & 2 \\
$\mathrm{EE}_{9}$ & - & - & 1 & 5 & 1 & 2 & 1 & 3 & - & - & 1 & 2 \\
\hline
\end{tabular}

\section{Avaliação da Predisposição dos Estudantes ao Uso e Abuso de Bebidas Alcoólicas}

A aplicação do CAGE foi orientada tomando-se como marco ou ponto de corte duas ou mais respostas positivas, aliado aos questionamentos abertos e introdutórios que antecederam a aplicação do questionário. Foram eles: "O Senhor(a) bebe?". "Então, vamos conversar sobre seu hábito de bebida?". Aqueles que relataram o abandono do hábito da bebida alcoólica por um prazo superior a um ano foram considerados excluídos do estudo. Uma única resposta positiva ao CAGE após sua aplicação poderia justificar uma avaliação posterior mais detalhada ${ }^{19}$, apesar de neste momento não ser um dos objetivos do estudo. 
Apesar disso, foi sugerida a busca de suporte na rede de serviços substitutivos do município de Natal/RN, ou outros de livre escolha.

Geralmente, o hábito de beber incomoda as pessoas em volta e os próprios sujeitos, pois deveriam diminuir e/ou interromper o uso da bebida a fim de evitar a ressaca ou o nervosismo, antes que as exigências etílicas os induzissem a beber, conforme observado na Tabela 2.

\section{Tabela 2:}

Distribuição percentual e absoluta das respostas ao questionário CAGE pelos estudantes de Enfermagem da UFRN. Natal/RN Junho/2006.

\begin{tabular}{lcc}
\hline \multicolumn{1}{c}{ QUESTIONÁRIO } & Freqüência & $\begin{array}{c}\text { \% } \\
(\mathbf{N = 4 2 )}\end{array}$ \\
\hline Cut down = diminuir & 19 & 33 \\
Annoyed = aborrecer & 14 & 46 \\
Guilt $=$ culpa & 8 & 17 \\
Eye opening = ao despertar & 1 & 4 \\
\hline
\end{tabular}

Preferencialmente, seguiu-se a ordem das perguntas e do seu significado. As respostas dadas ao CAGE pelos alunos de Graduação em Enfermagem (Tabela 2) revelaram positividade para as perguntas do questionário, onde $33 \%$ assumem que deveriam diminuir a quantidade de bebida ou interromper 0 consumo, $46 \%$ sentem-se aborrecidos quando pessoas 0 criticam pelo seu modo de beber, $17 \%$ sentem-se culpados pela maneira com que costumam beber, e $4 \%$ costumam beber pela manhã para diminuir o nervosismo ou a ressaca. Relembrase que há positividade para mais de uma resposta obtida a cada pergunta do instrumento adotado.

Chama-se a atenção para o consumo recorrente de bebidas alcoólicas no combate à indisposição causada pela interrupção do uso. 0 uso e a dependência do álcool representam um risco à saúde, um prejuízo ao processo ensino-aprendizagem do aluno.

As manifestações físicas (Tabela 3) são aquelas referidas quando o usuário sente-se mal fisicamente por ter bebido (34\%). Entre as demais respostas, $28 \%$ afirmaram que, quando bebem, tropeçam, cambaleiam e trançam as pernas, $24 \%$ afirmam que após beber sentem muito calor e sudorese.

Os sintomas físicos descritos identificam o grupo de alunos do $5^{\circ}$ período letivo do $1^{\circ}$ semestre de 2006 como o maior usuário de bebida alcoólica entre os entrevistados. Ressalta-se que 0 instrumento adotado possibilitou ao estudante de Enfermagem dar mais de uma resposta sobre um sintoma físico, mental ou emocional.

Tabela 3:

Distribuição percentual e absoluta dos sintomas físicos apresentados pelos estudantes de Enfermagem da UFRN. Natal/RN Junho/2006.

\begin{tabular}{|c|c|c|c|c|c|c|c|c|c|c|}
\hline \multirow{3}{*}{ Sintomas Físicos e Fisiológicos } & \multirow{2}{*}{\multicolumn{2}{|c|}{$\begin{array}{l}\text { Sintomas } \\
\mathrm{EE}_{1}\end{array}$}} & \multirow{2}{*}{\multicolumn{4}{|c|}{$\begin{array}{l}\text { Manifestos nos Seis } \\
\mathrm{EE}_{2} \quad \mathrm{EE}_{3}\end{array}$}} & \multirow{2}{*}{$\begin{array}{l}\text { Períodos L } \\
\mathrm{EE}_{4}\end{array}$} & \multicolumn{3}{|c|}{ Letivos Iniciais } \\
\hline & & & & & & & & $\mathrm{EE}_{5}$ & & $\mathrm{EE}_{6}$ \\
\hline & $\%$ & $\mathrm{~F}$ & $\%$ & $F$ & $\%$ & $\mathrm{~F}$ & $\% \mathrm{~F}$ & $\%$ & $F$ & $\%$ \\
\hline $\begin{array}{l}\text { Tremores nas mãos quando pára de - } \\
\text { beber por algumas horas }\end{array}$ & - & - & - & - & - & - & - - & - & - & - \\
\hline Sente-se fisicamente mal por ter bebido 1 & 10 & 1 & 10 & 3 & 30 & 1 & 104 & 40 & $0-$ & - \\
\hline $\begin{array}{l}\text { Quando bebe, tropeça, cambaleia e } 1 \\
\text { trança as pernas }\end{array}$ & 13 & 1 & 13 & 3 & 37 & - & -3 & 37 & 7 - & - \\
\hline $\begin{array}{l}\text { Após beber sente-se com muito calor e } 1 \\
\text { sudorese }\end{array}$ & 14 & - & - & - & - & 1 & 145 & 72 & $2-$ & - \\
\hline $\begin{array}{l}\text { Sente o coração bater rapidamente após - } \\
\text { ter bebido }\end{array}$ & - & - & & - & - & - & 4 & - & - & - \\
\hline
\end{tabular}

Os danos cerebrais causados pelo álcool são irreversíveis a partir de certo grau de comprometimento.

Em relação aos sintomas mentais e emocionais (Tabela 4), $42 \%$ dos estudantes informaram que, depois de beber em excesso, o raciocínio torna-se lento, 34\% já apresentaram "perda de memória" após beber e $14 \%$ ficaram desacordados.

Não menos importantes foram os sintomas com menor percentagem, dos quais $7 \%$ afirmaram que quando estão bebendo têm sensações estranhas e assustadoras e 3\% já apresentaram delirium tremens.

Sabe-se que os sintomas que caracterizam o uso do álcool se agravam e se intensificam ao longo da vida do usuário, gerando conseqüências físicas ligadas ao consumo abusivo (pancreatite, cirrose hepática), além dos problemas sociais, legais, trabalhistas, financeiros e de relacionamento ${ }^{20}$.

$04^{\circ}$ período foi o que mais se destacou quanto aos sintomas mentais e emocionais (Tabela 4), contrariamente ao apresentado pelos alunos do $5^{\circ}$ período com prevalência dos sintomas físicos (Tabela 3). Mediante tal correlação, estes grupos de alunos ( $4^{\circ}$ e $5^{\circ}$ períodos) apresentam uma predisposição ao uso abusivo ou problemático da bebida alcoólica, requerendo encaminhamento a serviços de saúde mental para avaliação das potencialidades e vulnerabilidades decorrentes desta problemática. 


\section{Tabela 4:}

Distribuição percentual e absoluta dos sintomas mentais apresentados pelos estudantes de Enfermagem da UFRN. Natal/RN - Junho/2006.

\begin{tabular}{|c|c|c|c|c|c|c|c|c|c|c|c|c|}
\hline \multirow[t]{2}{*}{ Sintomas mentais e emocionais } & \multicolumn{3}{|c|}{$\begin{array}{l}\text { Sintomas } \\
\mathrm{EE}_{1}\end{array}$} & \multicolumn{3}{|c|}{$\begin{array}{ll}\text { Manifestos } & \text { nos Seis } \\
\mathrm{EE}_{2} & \mathrm{EE}_{3}\end{array}$} & \multicolumn{2}{|c|}{$\begin{array}{l}\text { Períodos L } \\
\mathrm{EE}_{4}\end{array}$} & \multicolumn{4}{|c|}{$\begin{array}{ll}\text { Letivos } & \text { Iniciais } \\
\qquad E_{5} & \mathrm{EE}_{6}\end{array}$} \\
\hline & $F$ & $\%$ & $\mathrm{~F}$ & $\%$ & $F$ & $\%$ & $F$ & $\% \mathrm{~F}$ & $\%$ & $\% \mathrm{~F}$ & $\mathbf{F}$ & $\%$ \\
\hline Já teve delirium tremens & - & - & - & - & - & - & - & $-\quad-$ & - & -1 & 1 & 100 \\
\hline $\begin{array}{l}\text { Já teve momentos de "perda de } \\
\text { memória" após beber (sem ficar } \\
\text { desacordado) }\end{array}$ & - & - & 1 & 10 & 2 & 20 & 3 & 303 & 30 & 301 & 1 & 10 \\
\hline $\begin{array}{l}\text { Já ocorreu de ficar desacordado após } \\
\text { beber }\end{array}$ & 1 & 25 & 1 & 25 & 1 & 25 & 1 & $25-$ & - & $-\quad-$ & - & - \\
\hline $\begin{array}{l}\text { Depois de beber em excesso o } \\
\text { raciocínio ficou lento }\end{array}$ & 2 & 17 & 1 & 8 & 2 & 17 & 3 & 254 & 33 & $33-$ & - & - \\
\hline $\begin{array}{l}\text { Tem sensações estranhas e } \\
\text { assustadoras quando está bebendo }\end{array}$ & 2 & 100 & - & - & - & - & - & $-\quad-$ & - & $-\quad-$ & - & - \\
\hline
\end{tabular}

\section{CONSIDERAÇÕES FINAIS}

Atingiu-se o objetivo ao analisar a predisposição ao uso e abuso de álcool entre os estudantes do Curso de Graduação em Enfermagem da UFRN, indo além da responsabilidade pela promoção da saúde de um grupo, pois o processo ensino-aprendizagem dos acadêmicos de Enfermagem encerra o cuidar/cuidado que deve ampliar a instrumentalização e a compreensão do uso na vida de drogas, lícitas ou ilícitas, de forma efetiva e eficaz.

0 perfil obtido indica a predominância feminina na formação e exercício profissional e no uso do álcool, com idade média de 21 anos, solteiras, residentes com os pais e sem vínculos trabalhistas. Observou-se uma predisposição ao consumo de bebidas alcoólicas principalmente nos cinco períodos iniciais, com riscos posteriores ao desenvolvimento do abuso, ou da dependência.

Salienta-se que o uso problemático do álcool, além de ser um indicador de anos de vida perdidos, tem reflexo significativo sobre o aumento dos anos ajustados a incapacidades por manifestações físicas, mentais e emocionais, causando impacto no sistema previdenciário e público de saúde do país, bem como na formação do enfermeiro, por ser um problema circunscrito à saúde mental e à saúde pública.

Independentemente dos fatores predisponentes e da especificidade do instrumento utilizado, o presente estudo considera o uso do álcool um agravante no equilíbrio da vida pessoal e profissional. Destaca-se a relevância de outros estudos sobre 0 uso do álcool em mulheres ${ }^{4,21}$ e, particularmente, na Enfermagem ${ }^{22-24}$, apontando para o uso do álcool, sua freqüência ocasional e a dependência química evidente. Nesse sentido, pesquisas ${ }^{24-26}$ assinalam as evidências dessa problemática, respeitada a distinção entre as mesmas.

A primeira diz respeito ao padrão de uso de bebidas alcoólicas observado entre graduandas de Enfermagem de uma universidade paulista estadual com consumo moderado, indicativo de possível risco para a saúde ${ }^{24}$. A segunda destaca a propensão para o desenvolvimento do alcoolismo entre as estudantes de Enfermagem, sendo considerada alta, porém, maior entre os homens ${ }^{25}$. Tanto aquele como este estudo chamam atenção para o prejuízo potencial à saúde do futuro profissional de enfermagem.

A terceira pesquisa afirma que o beber problemático é recorrente entre universitários e está associado a inúmeras conseqüências negativas; nela, $44 \%$ dos participantes eram consumidores de risco e $48 \%$ possuíam expectativas positivas altas. Entre estas, facilitação das interações sociais, diminuição e/ou fuga de emoções negativas, ativação e prazer sexual, efeitos positivos na atividade, no humor e na avaliação de si mesmos ${ }^{26}$.

É imprescindível a implementação de estudos periódicos de avaliação da predisposição para o consumo de bebidas alcoólicas entre universitários de Enfermagem; maior ênfase aos conteúdos curriculares de Enfermagem, quer no modelo clínico, quer no epidemiológico, sobre o uso do álcool ocasional e problemático, com ênfase na atenção básica à saúde.

Reconhece-se que os achados são incipientes, demandam maiores investigações sobre o uso problemático do álcool no gênero feminino, particularmente na população jovem e nas futuras profissionais de enfermagem. Embora não tenha sido a pretensão deste, ousa-se, preliminarmente, identificar a partir da nossa realidade um novo campo de estudos com ênfase no uso de álcool, ou no seu uso problemático, através da utilização das técnicas da dinâmica de grupo como supor te terapêutico, objetivando-se a instrumentalização e implantação da EDIB no grupo investigado. Aliado a isto, e na mesma dimensão significante, subsidiar o projeto já existente, denominado "Viva a Vida sem Muros", que encerra atividades extensionistas, de pesquisa, e cenários de práticas disciplinares do Curso de Graduação em Enfermagem da UFRN nos Centros de Atenção Psicossocial (CAPS) dos Municípios de Parnamirim e Natal, ambos no Estado do Rio Grande do Norte. 


\section{Referências}

1. Zeferino MT, Santos VEB, Radünz V, Carraro TE, Frello AT. Enfermeiros e uso abusivo de drogas comprometendo o cuidado de si e do outro. Rev Enferm UERJ 2006 out/dez; 14(4): 518-23.

2. Ministério da Saúde (BR). A política do Ministério da Saúde para atenção integral a usuários de álcool e outras drogas. Brasilia (DF); 2003.

3. Carlini EA, Galduróz ICF, Noto AR, Nappo AS. I levantamento domiciliar sobre o uso de drogas no Brasil: estudo envolvendo as 107 maiores cidades do país - 2001.São Paulo(SP): CEBRID/ UNIFESP; 2002.

4. Galduróz JCF, Noto AR, Nappo AS, Carlini EA. Uso de drogas psicotrópicas no Brasil: pesquisa domiciliar envolvendo as 107 maiores cidades do país - 2001. Rev Latino-am Enfermagem 2005 set/out; 13(n esp): 888-95.

5. Kaplan HI, Sadock BJ. Compêndio de psiquiatria dinâmica. Porto Alegre (RS): Artes Médicas; 1993.

6. Pérez A, Mejías I. Patrones de interacción de la familias en las que no hay consumidores de sustancias psicoactivas. Rev Latino-am Enfermagem 1998; 10(2): 111-19.

7. Pillon SC, Luis MAV. Modelos explicativos para o uso de álcool e drogas para a enfermagem. Rev Latino-am Enfermagem 2004; 12(4): 676-82. 8. Laranjeira R, Pinsky I. Alcoolismo. São Paulo (SP): Contexto; 1998.

9. Gigliotti A, Bessa MA. Síndrome da dependência do álcool: critérios diagnósticos. Rev Bras Psiquiatr 2004 maio; 26(supl1): 11-13.

10. Presidência da República (BR). Política Nacional Antidrogas. Brasília (DF); 2003.

11. Minto EC, Corradi-Webster CM, Gorayeb R, Laprega MR, Furtado ER. Intervenções breves para o uso abusivo de álcool em atenção primária. Epidemiol Serv Saude 2007 jul/set; 16(3): 207-20.

12. Miranda FAN, Simpson CA, Azevedo DM, Costa SS. 0 impacto negativo dos transtornos do uso e abuso do álcool na convivência familiar. Rev Eletr Enferm [periódico on line] 2006; [citado 10 out 2006]; 8(2): 222-32. Disponível em: http://www.fen.ufg.br/revista/revista8_2/pdf/v8n2a07.pdf

13. Graeff FC. Drogas psicotrópicas e seu modo de ação. $2^{\mathrm{a} e d}$ São Paulo (SP): EPU; 1990.

14. Pillon SC, O'Brien B, Chavez KAP. A relação entre o uso de drogas e comportamentos de risco entre universitários brasileiros. Rev Latino-am Enfermagem 2005 nov/dez; [citado 10 out 2006]; 13 (n esp): 1-8. Disponível em: http://www.scielo.br/pdf/rlae/v13nspe2/pt_v13nspe2a11.pdf

15. Polit DF, Beck CT, Hungler BP. Fundamentos de pesquisa em enfermagem. $5^{\mathrm{a}}$ ed. Porto Alegre (RS): Artmed; 2004.

16. Gil AC. Como elaborar projetos de pesquisa. $4^{\mathrm{a}}$ ed. São Paulo (SP): Atlas; 2002.

17. Formigoni MLOS, Castel S. Escalas de avaliação de dependência de drogas: aspectos gerais. Rev Psiquiatr Clin [periódico on line] 1999; [citado 23 ago 2006]; 26(1): [aprox. 9 telas]. Disponível em: http://www.hcnet.usp.br/ipq/revista/r261/artigo(5).htm
18. Ewing JA, Rouse BA. Identifying the hidden alcoholic. In: Program and abstracts of the 29 th Internacional Congress on Alcohol and Drug Dependence. Sidney; 1970.

19. Masur J, Monteiro MG. Validation of the "CAGE" alcoholism screening test in a brazilian psychiatric inpatient hospital setting. Braz J Med Biol Res 1983; 16(3): 215-18.

20. Vaissmam M. Alcoolismo no trabalho. Rio de Janeiro (R): FIOCRUZ; 2004

21.Santana VS, Almeida Filho N. Alcoolismo e consumo de álcool: resumo de achados epidemiológicos. Rev ABPAPAL 1987; 9: 15-22.

22. Ramos LH, Pillon SC, Cavalcante MB, Luiz MAV, Padredi F, Laranjeira RR. 0 ensino sobre dependência química em cursos de graduação de enfermagem no Brasil, 1998. Acta Paul Enferm 2001; 14(3): 35-43.

23. Luis MAV, Pillon SC. 0 conhecimento dos alunos de enfermagem sobre álcool e drogas. Rev Eletr Enferm [periódico on line] 2003; [citado 23 ago 2006]; 5 (1): 21-7. Disponível em: http:// www.fen.ufg.br/revista/revista5_1/pdf/drogas.pdf

24. Chavez KAP, O'Brien B, Pillon SC. Uso de drogas e comportamentos de risco no contexto de uma comunidade universitária. Rev Latino-am Enfermagem. [periódico on line] 2005; [citado 10 ou. 2006]; 13(n esp): [aprox 7 telas]. Disponível em: http://www.scielo.br/pdf/rlae/ v13nspe2/pt_v13nspe2a14.pdf

25. Rodrigues AP, Oliveira AS, Zaleski EGF, Arantes SL. Avaliação do nível de propensão para o desenvolvimento do alcoolismo entre estudantes do curso de graduação em enfermagem da Universidade Católica Dom Bosco. Rev Eletr SMAD [periódico on line] 2007; [citado 10 ago 2007]; 3(1): 1-11. Disponível em: http://redalyc.uaemex.mx/ redalyc/pdf/803/80330104.pdf

26. Peuker AC, Fogaça J, Bizarro L. Expectativas e beber problemático entre universitários. Psicologia: teoria e pesquisa 2006 maio/ago; 22(2): 193-200.

\section{Nota}

Esta pesquisa integra as atividades do Grupo de Estudos, Pesquisa e Trabalho: VIVA A VIDA SEM MUROS - Base de Pesquisa III (BCD108-ENFERMAGEM CLÍNICA/CNPq/PROPESQ/UFRN), com a participação de alunos de iniciação científica, extensão, monitoria, voluntariado, mestrado, docentes e profissionais enfermeiros dos serviços de saúde mental e psiquiátricos. Pesquisas em desenvolvimento pelo Grupo cadastradas na PROPESQ/UFRN e aprovadas pelo Comitê de Ética em Pesquisa/UFRN: 0 Transtorno Mental na Interface da Vida dos Servidores da Universidade Federal do Rio Grande do Norte; Os Centros de Atenção Psicossocial (CAPS) no Município de Natal-RN: Representações Sociais de Familiares; Avaliação dos Fatores que Interferem na Atenção à Saúde Mental na Estratégia Saúde da Família no Município de Parnamirim/RN - EDITAL - MS/PPSUS/CNPQ/FAPERN - N01/2007. 